\title{
Suggestions for Enhancement of Cultural Tourism at the Candle Festival of Ubon Ratchathani
}

\author{
Suchart Suwanvong ${ }^{1}$, Pisit Boonchai ${ }^{1} \&$ Somkhit Sukerb ${ }^{1}$ \\ ${ }^{1}$ The Faculty of Cultural Science, Mahasarakham University, Khamriang Sub-District, Kantarawichai District, \\ Maha Sarakham Province, Thailand \\ Correspondence: Suchart Suwanvong, The Faculty of Cultural Science, Mahasarakham University, Khamriang \\ Sub-District, Kantarawichai District, Maha Sarakham Province 44150, Thailand. E-mail: \\ ssuwanvong125@outlook.com
}

Received: July 3, 2014 Accepted: July 18, 2014 Online Published: September 22, 2014

doi:10.5539/ach.v7n1p115 URL: http://dx.doi.org/10.5539/ach.v7n1p115

\begin{abstract}
The aims of this qualitative research were to study the history of the tien pansa candle festival in Ubon Ratchatani and make suggestions to enhance cultural tourism. The research results found that the festival is based on the custom of offering candles as a method of worship. There are six reasons why the Ubon Ratchatani candle festival is able to continue in modern Thailand: a) Ubon Ratchatani is a Buddhist stronghold; b) the local people are accommodating; c) the city is surrounded by key resources for candle-making; d) the people of the city hold true to Buddhist values; e) there are many talented artisans; g) primary aims of promoting Buddhism and respecting traditions are upheld. Nevertheless, current organization of the festival suffers from some problems, notably increased consumerism and cultural displacement. The best solution is to encourage more local participation in festival development, planning and organization.
\end{abstract}

Keywords: candles, Isan, organization, conservation, participation, traditions

\section{Background}

Tourists are attracted by foreign and exotic culture. Cultural tourism is a product of this attraction and its main selling points are everyday life, customs and faith. To successfully manage tourism, it is imperative to focus on each of the aforementioned factors. Having said this, management must refrain from altering or influencing traditional culture in any way. Instead, tourism initiatives must highlight and exploit the considerable value of original local traditions (Wankaew, 2002). Foreign visitors must not alter the area they are visiting in any way. Instead, the locality must benefit from tourism, through conservation. This will generate the maximum possible revenue streams for the community.

Thai ceremonies are based on the individual identity of the local community, their everyday life, faith and traditional knowledge from which local peculiarities are derived. Global tourists consider these as imperative and for successful cultural tourism, they must be maintained. In light of this, the Thai government set out a development plan for tourism for the period 2012 to 2016. The of the plan was to increase tourism in Thailand, so to maximize potential income, value and growth (Ministry of Tourism and Sports, 2012, p. 1).

Isan is the common name for the vast Northeastern region of Thailand. The area is home to many interesting natural and cultural attractions, largely due to the melting pot of ethnic groups living within its boundaries. Local traditions are clear manifestations of ancient culture in the modern world (Jamrik, 2000, pp. 8-9). An increasingly narrow and more accessible world society has caused the emergence of a number of threats to the traditional cultural order, most notably, cultural dilution, homogenization and displacement by foreign cultures (Wankaew, 2002). Cultural diffusion is the byproduct of our modern world and is a direct threat to Isan traditions. The importance of local culture can be seen in its continued place in local life. Ancestral traditions are still practiced in Isan communities and are strongly associated with Buddhism. One such tradition, the candle festival of Ubon Ratchatani Province is a particularly large attraction for visitors. It responds to government policies regarding the preservation and maintenance of traditional local culture by providing an opportunity for communities to showcase the customs of their descendents and celebrate their unique local identity ( $\mathrm{Na}$ Ubon, 2002). 
Tien pansa, the Thai name for the candle festival, has developed rapidly in recent years and attracts large numbers of visitors - many more than in the past. The effect on the local economy is extremely positive. The festival is characterized by its parades, its beauty contests and its candle competitions. The festival lasts for 3 days. Despite the traditional groundings of tien pansa, recent versions of the festival have incorporated more technological developments, which threaten to completely replace the original customs. Attitudes regarding worship, funding and organization have also changed and now it is rare for locals to participate in day-to-day management of the festivities (Aneksuk, 2001). Recent evaluations of the festival have concluded that a number of areas are inadequate for a festival of its size and repute. Additionally, research has found the festival facilities, amenities and tourist provisions to be insufficient (Kawila, 2001; Pakdeepinit, 2007). Also, the local ethnic identity of the people and the festival must be upgraded to a focal point of the festival (Boonyanupong, 2001). Given this background, the research team conducted this investigation to design a model of conservation for the candle festival of Ubon Ratchatani Province.

\section{Methodology}

The aims of this qualitative research were to study the history of tien pansa in Ubon Ratchatani and make suggestions to enhance cultural tourism. The research lasted from July 1, 2012 until July 25, 2013. This is a qualitative research, for which Ubon Ratchatani was purposively selected as the research area, given its status as the only province to hod the tien pansa festival on such a large scale. The research sample was identified as 115 informants. The informants were divided into three groups: 20 key informants, 45 casual informants and 50 general informants. Documentary analysis and field study were both employed to collect data pertaining to the research objectives. Research tools were comprised of basic survey, observation, interview and focus group discussion. All collected data was validated by triangulation, according to date of collection, location, researcher and method. The data was classified according to the research aims and analyzed by typological analysis and analytic induction. The findings are here displayed in the form of descriptive analysis.

\section{Results}

The $K a$, also known as Suay, or even Kuay were the first indigenous group to settle in and around present-day Ubon Ratchatani. These people were of Mon-Cambodian decent and their traditional practices and everyday lifestyle have played a large part in shaping the modern Ubon Ratchatani customs. From 1792 onwards, people living near dong-oo-peung used candles to display their faith and worship (dong-oo-peung relates to the location of present-day Ubon Ratchatani). Candles thus became sacred items used for worship. Tien pansa developed from local beliefs, known as the heed sip song. The heed sip song relates to intense monthly worship for the course of twelve months and is observed by the majority of Isan people. According to the beliefs of local people, candles create additional merit for those who use them. People now commonly offer candles to monks at times of worship, which are required by monks to light their temples throughout Vassa, a three-month holy period. Tien pansa was first celebrated as a ceremony when local Buddhists created bundles of small candles, tied together on a wooden splint. The bundles were then covered in colored paper, making a don-tien (candle trunk), which is known as tien-mad-ruam.

After 1952, candle creation was recognized as an art form. It took two distinct forms: mad-ruam-dit-lai, whereby the candles were wrapped and decorated with patterns and dit-pim, whereby the candles were decorated with print. Now, three styles are used: original covered and decorated candles, candles adorned with print and candles shaped by carving. During the 1957 geung-puttakarn festival commemorating the Buddha's lifetime, the candle festival in Ubon Ratchatani was granted higher sponsorship. Despite this bonuse, the candle competitions were stopped in 1967 because of complaints about corrupt and unfair judging in the previous annual festival. The locals missed the festival and vowed to organize the biggest and best incarnation of the event in living memory the following year. Consequently, carved candles first appeared in competitions during the festival of 1968. TAT (Tourist Authority of Thailand) observed the celebrations in 1976 and considered the event so valuable that from 1977 onwards, increasingly important and impressive tien pansa celebrations have been held. From 1977, many visitors have come to experience the beauty of the festival first-hand, promoting tien pansa to a position as the emblem of Ubon Ratchatani.

There are six reasons why the Ubon Ratchatani candle festival is able to continue in modern Thailand: a) Ubon Ratchatani is a Buddhist stronghold; b) the local people are accommodating; c) the city is surrounded by key resources for candle-making; d) the people of the city hold true to Buddhist values; e) there are many talented artisans; g) primary aims of promoting Buddhism and respecting traditions are upheld.

Some problems were found with festival development. Tourists have negatively affected local traditions. Belief in candles as objects for worship has been diluted and consequently the customs displayed during the festival are 
not true to everyday practice. This causes the celebrations to be a show rather than a reflection of everyday life in the local communities. Moreover, there are insufficient numbers of craftsmen with the required technique and ability to create suitable candle designs to be used during the festivals. This means that artisans must be hired from elsewhere and diminishes local influence in the day-to-day management and content of the festival. Local participation has also been negatively affected by a shift in emphasis from worship to consumerism. Big businesses the sponsor the festival and demand a bigger role in its management. Often the sponsors are not local residents and do not possess the required knowledge base to accurately reflect local lifestyle, customs and traditions. This has the side-effect of reducing community interest in the festival and thus causing the number of trained and interested candle craftsmen to diminish. Candles are made with the objective of winning prizes rather than worship. This, combined with the fact that temples create the candles as opposed to local people, contradicts the original aims of tien pansa. As temples must hire expert carvers to create their candles, the candle competition has become a privilege of wealthy communities. Those without adequate funding will be unable to compete and unlikely to enter in years to come. Additionally, the candles do not reflect or represent local identity. Nevertheless, the procession itself remains true to the stylistic traditions and postures of Ubon Ratchatani dance, although it is made too long by the high number of entrants.

With these problems in mind, the research team and informants devised the following solutions:

- The true essence of Ubon Ratchatani community life must be reflected by the ceremony.

- The festival host must be appropriate and advertising should be developed.

- There must be encouragement and incentives for young people to participate in and attend tien pansa.

- Conservation of local traditions must take the form of local events and could include candle carving training workshops at local schools.

- There needs to be an increase in the candle creation budget and a more developed network of sponsors.

- The importance of festival performances must be raised to reflect their popularity among foreign tourists.

- The role of the local community must be raised to be on a par with that of the government and the private sector.

- The parades and performances must start at $6 \mathrm{pm}$.

- Pride and satisfaction must be sufficient motivation for entering the candle competition, rather than prizes.

- Judges must be fair, impartial and transparent in their interpretation of competition rules.

- There must be levels of prize to reflect the cost of the candle and increase the opportunity for communities with small budgets.

- There must be an additional category in the candle competition for ancient styles, in order to preserve former provincial traditions. North-eastern Thai styles must also be incorporated in designs.

The aforementioned concerns may result in the disappearance of local traditions and culture from Ubon Ratchatani communities. By implementing the suggestions given above and increasing emphasis on traditional practices in local education, they may continue under the guidance of future generations.

\section{Discussion}

Tien pansa is a strong cultural festival. Alfred Kroeber hypothesized that the ideas of one culture move into other cultures over time. Strong social cultures are absorbed by weaker cultures, displacing and altering them from within. Tien pansa in Ubon Ratchatani is the biggest of its kind in Thailand and has not been affected by other ceremonies from the local vicinity, which points to the conclusion that the candle festival is a strong culture (Kroeber, 1940).

The results here correspond to those of Sakchai Utito (2007). Utito found that designs for candles are influences by everyday life, faith and traditions. The festival history determined by this investigation agreed with the findings of Busaba Kitijantaropat (2008), which recognized the value of candles for in local society and their place in ceremonies as offerings or gifts.

This study identified a number of problems with tien pansa. These include the increasing role of global culture. From 1977, many visitors have come to experience the beauty of the festival first-hand, promoting tien pansa to a position as the emblem of Ubon Ratchatani. However, the increased reputation and demand on the festival has led to incorporation of more technological developments, which threaten to completely replace the original customs. Attitudes regarding worship, funding and organization have also changed and now it is rare for locals to 
participate in day-to-day management of the festivities (Aneksuk, 2001). Also, the local ethnic identity of the people and the festival must be upgraded to a focal point of the festival (Boonyanupong, 2001). These are all examples of cultural diffusion, yet consider tien pansa as a weak culture influenced by stronger social trends of the West (Kroeber, 1940). If tien pansa is to remain, there must be encouragement and incentives for young people to participate in and attend the festival. Yuwat Wuttimetee (1993) explained that the role of the local community must be raised to be on a par with that of the government and the private sector because community participation is imperative to the future success of tien pansa traditions (Boonjaeng, 2003; Boonyanupong, 2001; Panet, 1998).

By implementing the suggestions given above and increasing emphasis on traditional practices in local education, they may continue under the guidance of future generations. Therefore, the best solution is to encourage more local participation in festival development, planning and organization.

\section{References}

Aneksuk, B. (2001). The government and cultural financing: A case study of the tien pansa processions in Ubon Ratchatani. Nakhon Pathom: Mahodol University.

Boonjaeng, B. (2003). Local community participation in conservational tourism in Baan Koh Bak Jan, Pra Nakhon Sri Ayutthaya. Ayutthaya: Local Research Council.

Boonyanupong, W. (2001). Community participation in the conservation of community culture: A case study of the Mon community in Baan Koh Kred, Bak Kred, Nonthaburi. Bangkok: Ramkamhaeng.

Department of Tourism. (2013). Tourist Statistics. Retrieved March, 2013, from http://www.tourism.go.th

Jamrik, S. (2000). Cerebral storehouse of the poor. Bangkok: Duean Dula Printers.

Kawila, J. (2001). Choices of cultural tourism: A case study of Baan Wua Lai, Mueang District, Chiang Mai Province. Chiang Mai: Chiang Mai University.

Kitijantaropat, B. (2008). Tien pansa: Management model for creating participation in the inheritance of the tien pansa candle procession in communities of Ubon Ratchatani. Maha Sarakham: Mahasarakham University.

Kroeber, A. L. (1940). Stimulus diffusion. American Anthropologist, 42(1), 1-20. http://dx.doi.org/10.1525 /aa.1940.42.1.02a00020

Ministry of Tourism and Sports. (2012). 2012-2016 national tourism development plan. Bangkok: Ministry of Tourism and Sports.

Na Ubon, B. (2002). 200 Years of Ubon. Bangkok: Chuan Publishers.

Pakdeepinit, B. (2007). Participation in sustainable tourism. Nakhon Phanom: Mahidol University.

Panet, O. (1998). Assessment of the need for participation and development of tourism for the public. Chiang Mai: Chiang Mai University.

Utito, S. (2007). The creative evolution of tien pansa: A case study of award winners in the tien pansa contest from 2003 to the present day. Maha Sarakham: Mahasarakham University.

Wankaew, S. (2002). Confrontations with global culture: Cultural policies in new contexts. Bangkok: Duean Dula Printers.

Wuttimetee, Y. (1993). Basis for the development of communities and their people. Bangkok: Thais Helping Thais Partnership.

\section{Copyrights}

Copyright for this article is retained by the author(s), with first publication rights granted to the journal.

This is an open-access article distributed under the terms and conditions of the Creative Commons Attribution license (http://creativecommons.org/licenses/by/3.0/). 